\title{
INFLUÊNCIA DO PENSAMENTO CÉTICO NA PRÁTICA DO DESIGN MODERNO COM FOCO NA VALIDAÇÃO
}

The influence of skeptical thought in the practice of modern design focusing on validation

GOULART ,Michela Cristiane França I Mestranda em Gestão de Design

Universidade Federal de Santa Catarina - UFSC I michela.designer@gmail.com

JUNIOR ,José Elias da Silva I Mestrando em em Gestão de Design

Universidade Federal de Santa Catarina - UFSC I eliasjr2@gmail.com

REIS ,Paulo Fernando Crocomo dos I Mestrando em em Gestão de Design Universidade Federal de Santa Catarina - UFSC I pcrocomo@gmail.com

PERASSI, Richard Luiz de Sousa I Doutor em Comunicação e Semiótica - PUC SP MERINO, Eugenio Andres Diaz I Doutor em Engenharia da Produção - UFSC GONÇALVES, Marilia Matos I Doutora em Engenharia da Produção - UFSC

\begin{abstract}
Resumo
A validação é uma etapa metodológica do design e ocorre pelo pensamento cético que duvida da capacidade dos sentidos em reconhecer os objetos tais quais são em si mesmos. $O$ artigo objetiva compreender, por uma reflexão sistemática, a influência e a aplicação do pensamento cético filosófico na validação como processo de design. Foi realizada uma pesquisa bibliográfica de natureza aplicada e abordagem qualitativa. Como resultado foi gerado um quadro ilustrativo do design contemporâneo através do ceticismo. A relevância da filosofia no design se evidencia na disposição a reflexão e análise da prática do design quanto a seus

\section{Abstract}

Validation is a methodological step of the design and the thought occurs skeptic who doubts the ability of the senses to recognize such objects which are in themselves. The article aims to understand, for a systematic reflection, influence and application of skeptical thought philosophical validation and design process. Was performed bibliographic search of an applied nature and qualitative approach. As a result we created a table illustrating the contemporary design by skepticism. The relevance of philosophy in design is evident in the provision reflection and analysis of design practice as its methods and results.
\end{abstract} métodos e resultados.

Palavras-chave: Design. Ceticismo. Metodologia de Projeto. Filosofia.

KeyWords: Design. Skepticism. Design methodology. Filosofy. 


\section{INTRODUC̣̃̃O}

O ceticismo também denominado ceticismo pirrônico por remontar ao filósofo grego Pirro de Élis (364-275 a.c) é considerado por Verdan (1998, p. 37) uma atitude mental em colocar em questão a possibilidade de alcançar uma certeza qualquer. O ceticismo se posiciona entre a afirmação e a negação com a suspensão total de juízo e por este fato, é considerado o responsável pelo impulso criador da ciência (ALMEIDA, 2002).

A dúvida por excelência e o questionamento do conhecimento sensível e racional é característico do ceticismo e por tal razão, de certa forma, é radical pois duvida o conhecimento intelectual, universal, considerado imutável e absoluto (VERDAN,1998).

Segundo Almeida (2002, p. 197), o questionamento ceticista marca o espírito científico grego de tal modo que o homem grego "não era apenas cético, mas detinha um especial talento para converter o seu ceticismo em ciência".

No entanto, a ciência moderna se distanciou das origens do cientificismo grego, pois passa a adotar um método que de acordo com Almeida (2002, p. 197) "[...] significa 'caminho para ir em busca de algo' [...]", ou seja, pressupõe verificar uma verdade.

Dessa forma, o design como ciência moderna utiliza métodos, porém mantém aspectos céticos por questionar constantemente o conhecimento racional e sensível através da verificação, avaliação e validação que são etapas projetuais no processo de desenvolvimento de produtos-serviços.

Portanto, objetiva-se compreender a influência do pensamento cético na prática do design por meio de uma reflexão sistemática de questões da validação no processo de design em comparação com conceitos básicos derivados do ceticismo pirrônico. O método adotado é a pesquisa exploratória, que segundo Gil (2008), proporciona maior familiaridade com determinado problema. Foi utilizado a pesquisa bibliográfica em artigos científicos e livros relacionados ao tema de estudo, tendo como principal fundamentação o livro de Verdan (1998): O ceticismo filosófico.

A aproximação da filosofia no design garante o caráter dialético e polêmico próprio da filosofia, que segundo Dutra (2005), torna a atividade de pensar mais robusta, renova sistemas e teorias hegemônicas sobre o senso comum, as ciências técnicas, a natureza e a experiência vivida. 


\section{O Método no Design}

A possibilidade de estabelecer relações entre ceticismo e design neste artigo parte de dois pressupostos: o primeiro deles é do ceticismo não absoluto pois este não poderia nem perguntar, tendo em vista que toda pergunta orienta a uma possível resposta; mas como uma atitude adotada que não aceita o dogmatismo. Onde com a negação do dogmatismo, se reconhece que "os saberes historicamente condicionados e abertos" (ALMEIDA, 2002, p. 194).

Um segundo pressuposto é do design como ciência moderna, ou seja, apartir do uso do método no design. O método é uma série de atividades sistemáticas e racionais que permite alcançar conhecimentos válidos e verdadeiros, detectando erros e auxiliando a tomada de decisões com maior segurança e economia (LAKATOS; MARCONI, 1995). Almeida (2002, p. 194) numa passagem de Gadamer, esclarece a implicação do método na ciência:

Methodus significa 'caminho para ir em busca de algo'. O metódico é poder recorrer de novo o caminho andado, e tal é o modo de procedar da ciência. Mas isso supõe necessariamente uma restrição nas pretensões de alcançar a verdade. Se a verdade (veritas) supõe a verificabilidade - e uma ou outra forma -, o critério que mede o conhecimento não é já sua verdade, mas sim sua certeza. Por isso, o autêntico de éthos da ciência moderna é, desde que Descartes formulara a clássica regra de certeza, que ela só admite, como satisfazendo a condições da verdade, o que satisfaz o ideal da certeza.

A relação do design como ciência moderna se faz necessário pois se considerarmos que

Todos os homens são designers. Tudo o que fazemos, quase todo o tempo é design. O design é básico em todas as atividades humanas. Planejar e programar qualquer ato visando um fim específico, desejado e previsto isto constitui o processo de design [...] design é compor um poema épico, executar um mural, pintar uma obra de arte, escrever um concerto. Mas design é também limpar e organizar uma escrivaninha, arrancar um dente quebrado, fazeruma torta de maçã, escolher os lados de um campo de futebol e educar uma criança (PAPANEK, 1995, p. 27)

Nesse caso, podemos incorrer em retomarmos questões ontológicas do 
design, sendo que este não é o objetivo do artigo. Dessa forma, considera-se no contexto do artigo que "sem o método, o que resulta não é design, mas o acaso, que não permite valoração quantitativa e ou qualitativa, repetição ou aprimoramento" (LANA, 2011, p. 60).

No design, a introdução do método é atribuída à revolução industrial pelo desenvolvimento do modo de produção capitalista. A partir de então, o contexto histórico do design sofreu mudanças significativas e que, segundo Souza (2008), ocorreram a partir da industrialização da produção, do surgimento do projeto e da substituição da arte pela ciência. De acordo com o autor, esse design pós-revolução industrial ou design moderno é a atividade que objetiva o projeto de produtos industriais ou produtos que utilizem processos decorrentes ao desenvolvimento tecnológico. Se, no entanto, esta conceituação do design moderno exclui produtos que mantém processos manuais em seu desenvolvimento e também o próprio processo projetual, eminentemente resultado da manualidade do designer; por outro lado, demarca contextualmente o divisor de águas do design moderno- a revolução industrial e suas consequências no design pela introdução do método científico.

Após a segunda guerra mundial tendo como símbolo a Escola Superior da Forma de Ulm, o design busca a aplicação de métodos rigorosos no desenvolvimento dos projetos e substitui as concepções artísticas por princípios científicos no intuito de romper com a arte e ter sua autonomia no desenvolvimento (FONTOURA, 2009).

Fontoura (2009) afirma que o conhecimento científico, pelo uso de métodos rigorosos, permite a obtenção de um tipo de saber sistemático, preciso e objetivo. Apesar da precisão do uso do método, o design questiona e mantém sua atitude dubitativa em face do saber e da investigação, assim como o ceticismo (DUTRA, 2005).

Desta maneira, utiliza a validação como modo de assegurar que um produto, processo ou sistema atenda às especificações determinadas em um projeto de maneira satisfatória. Sendo assim, a validação no processo de desenvolvimento é determinante para o sucesso do projeto. Alguns autores tratam essa etapa com nomenclaturas diferenciadas para se referir ao mesmo objetivo de validação, como pode ser observado no Quadro 1.

Quadro 01- Método de validação segundo autores

\begin{tabular}{|c|c|c|}
\hline Autor & Método projetual & $\begin{array}{c}\text { Termo ado- } \\
\text { tado }\end{array}$ \\
\hline
\end{tabular}




\begin{tabular}{|c|c|c|}
\hline $\begin{array}{l}\text { Bürdek } \\
\text { (2006) }\end{array}$ & $\begin{array}{l}\text { a. Compreensão e definição do objetivo (ou missão). } \\
\text { b. Coleta de informações sobre o contexto objetivado. } \\
\text { c. Análise destas informações. } \\
\text { d. Desenvolvimento de conceitos e alternativas visando o objetivo. } \\
\text { e. Avaliação das alternativas encontradas. } \\
\text { f. Teste e implementação da solução escolhida. }\end{array}$ & Avaliação \\
\hline $\begin{array}{l}\text { Argan } \\
\text { (1993) }\end{array}$ & $\begin{array}{l}\text { a. Conhecimento relativo ao existente: conhecimento histórico das expe- } \\
\text { riências relacionadas ao objeto. } \\
\text { b. Análise e crítica do existente: apreciação crítica do objeto existente, } \\
\text { pois o projeto sempre vem em busca de mudar alguma realidade. } \\
\text { c. Hipótese: é uma base de possibilidades viáveis subordinada à imagi- } \\
\text { nação que estabelece a escolha de um dos caminhos dentro de tantas } \\
\text { possibilidades do projeto. }\end{array}$ & $\begin{array}{l}\text { Análise e } \\
\text { crítica }\end{array}$ \\
\hline $\begin{array}{l}\text { Munari } \\
\text { (1998) }\end{array}$ & $\begin{array}{l}\text { a. Problema: algo a ser resolvido. } \\
\text { b. Definição do problema: caracterização do problema a ser resolvido em } \\
\text { vista de um determinado tipo de solução. } \\
\text { c. Componentes do problema: subdivisão do problema em vários subpro- } \\
\text { blemas, para melhor conhecimento do mesmo. } \\
\text { d. Coleta de dados: coleta abrangente de dados relativos ao problema. } \\
\text { e. Análise de dados: análise sistemática dos dados coletados. } \\
\text { f. Criatividade: geração de proposiçães para solução do problema. } \\
\text { g. Materiais e tecnologias: pesquisa de materiais e tecnologias disponí- } \\
\text { veis à realização do projeto. } \\
\text { h. Experimentações: busca de relações úteis entre materiais e instrumen- } \\
\text { tos. } \\
\text { i. Modelos: desenvolvimento de modelos para demonstração de possibi- } \\
\text { lidades a serem empregadas no projeto. } \\
\text { j. Verificação: validação de resultados. } \\
\text { k. Desenho de construção: documentação técnica do projeto. } \\
\text { I. Solução: materialização do objeto. }\end{array}$ & $\begin{array}{l}\text { Verificação: } \\
\text { validação }\end{array}$ \\
\hline $\begin{array}{l}\text { Löbach } \\
\text { (2001) }\end{array}$ & $\begin{array}{l}\text { a. Fase de preparação / Análise do problema: conhecimento, coleta e } \\
\text { análise de informações. } \\
\text { b. Fase de geração / Alternativas do problema: escolha de métodos, } \\
\text { produção de idéias e geração de alternativas. } \\
\text { c. Fase de avaliação / Avaliação das alternativas do problema: exame de } \\
\text { alternativas, seleção e avaliação. } \\
\text { d. Fase de realização / Realização de solução do problema: desenvolvi- } \\
\text { mento e reavaliação. }\end{array}$ & Avaliação \\
\hline
\end{tabular}

Fonte: Autoria própria ,2013.

Os métodos de validação e as especificações variam conforme os objetivos ou fim que se destinam, podendo estar relacionados a atributos como: qualidade, inovação, acessibilidade, transnacionalidade... Destes, a validação é comumente associada a padrões de qualidade e se dá por vários aspectos, primeiramente por seu objetivo de adequação ao uso para atingir resultados satisfatórios (PALADINI, 2004) e também ao próprio caráter cético da qualidade de duvidar o produto por averiguar, testar, medir e certificar para a total aprovação com base nos requisitos.

Quanto aos benefícios da validação do produto no processo de design, além do cumprimento dos requisitos de projeto, podem ser quanto a reflexão sobre o produto em seus vários contextos de uso, a melhoria contínua da qualidade do produto, a credibilidade, confirmação do valor do produto...

O design também busca a validação de seus próprios métodos pela eflexão-na-ação. Teixeira (2011) afirma que a reflexão-na-ação acontece 
quando o profissional analisa como ocorre a prática profissional e como esta se caracteriza. Na reflexão-na-ação não se costuma adotar padrões, mas se mantém um olhar analítico e um caráter cético quanto ao processo para melhoria da atividade. Esta é uma prática para a expertise profissional, sendo constituída de habilidades tácitas com a experimentação (como ato criativo) e a crítica (como um ato reflexivo) de modo a se compreender e explicar a prática do design (TEIXEIRA, 2011). O que possibilita tornar o design verossímil tal qual o pensamento cético quando este se abstém de adotar uma postura dogmática e imutável.

\section{O Ceticismo no Design}

O ceticismo remonta ao filósofo grego Pirro de Élis (364-275 a.c). O pirronismo é considerado por Verdan (1998, p. 37), uma atitude mental em colocar em questão a possibilidade de alcançar uma certeza qualquer. O ceticismo se posiciona entre a afirmação e a negação com a suspensão total de juízo e por este fato, é considerado o maior desafio do pensamento filosófico. Segundo Zannete (2010) como Pirro nada escreveu, seu legado do pensamento cético foi transmitido por seus discípulos Eneisedemo (150- 70 a.c), Agripa (150-100 a.c), Sexto Empírico (150-100 a.c), entre outros.

Eneisedemo e Agripa formularam listas de modos ou tropos de se chegar à total suspensão de juízo. Agripa enuncia os cinco modos de suspensão de juízo que são, de acordo com Verdan (1998, p. 39):

1. Modo da discordância: relativo às diferentes opiniões dos homens;

2. Modo da regressão ao infinito: um argumento precisa de uma prova que precisa de outra e assim infinitamente;

3. Modo da relação: relação entre o sujeito e o objeto é relativa;

4. Modo do postulado: adotar uma hipótese para argumentar de nada adianta;

5. Modo do círculo vicioso: quando se assume como princípio de prova exatamente o que se deve provar.

Para Verdan (1998, p. 8), o ceticismo nunca alcançou a influência de outros pensamentos como o platonismo e aristotelismo porque este questionamento contraria a natureza humana de buscar verdades incontestáveis, que apoiam sua existência. Além disso, o autor também aborda a comum confusão entre 
o ceticismo e incredulidade, graças à atitude própria de Voltaire, que põem em dúvida a fé religiosa. Por outro lado, o ceticismo também se esforça em revelar os limites do racionalismo, preconizando a submissão às crenças religiosas.

O ceticismo deixou arraigado na ciência moderna seu olhar investigativo e por esse fato é possível relacionar o pensamento cético, definido por Verdan (1998, p. 38) como aquele que abstém de formular opiniões dogmáticas, de posição dubitativa e suspensão de juízo com o processo metodológico do design.

Para Norman (2006, p. 174), graças aos constantes testes, áreas problemáticas dos projetos de design são descobertas e modificadas. Depois disto, são novamente submetidas a outros testes e modificando até que o tempo, a energia e os recursos se esgotem. Este processo de validação, característico do trabalho do artesão, constitui o que Norman (2006, p. 175) nomeia por "hillclimbing" (escalar encosta).

Ainda relacionando-se o design ao ceticismo podemos exemplicar com a evolução do telefone descrita por Norman (2006, p. 175) no livro O design do dia a dia com o terceiro tropos de Agripa ou modo da relação, onde o conhecimento que temos dos objetos, à natureza do sujeito e às condições nas quais se encontra este objeto é relativo.

O telefone, como objeto representativo do processo de design, evoluiu ao longo de várias gerações. Norman (2006, p. 176) o descreve, na sua origem, como objeto desconfortável, composto por um telefone de mão e um microfone, onde cada um dos objetos era segurado separadamente. Era preciso girar a manivela para gerar um sinal que fazia tocar um sino do outro lado da linha. Com o passar dos anos, tamanho e forma foram aperfeiçoados, simplificando seu uso. As condições encontradas pelo objeto telefone durante seus primeiros anos de existência diferem das atuais. Na sua origem, evoluiu lentamente, protegido pelo status de monopólio dos sistemas telefônicos.

Atualmente, há necessidade de criar produtos que atraiam diferentes públicos, com funcionalidades e características também distintas para as necessidades individuais de cada indivíduo.

\section{Aplicação do pensamento de Enesidemo no Design Moderno}

O ceticismo questiona a capacidade dos sentidos em nos fazer conhecer os objetos tais quais são em si mesmos. Enesidemo enumera dez modos pelos quais se pode fazer esta afirmação, apresentadas por Verdan (1998) como: 
1. A diversidade dos animais;

2. A diversidade dos homens;

3. A diversidade dos sentidos;

4. As circunstâncias;

5. Os costumes, as leis, as opiniões;

6. As misturas;

7. As situações e as distâncias;

8. As quantidades ou composições;

9. Frequência e raridade;

10. A relação.

Verdan (1998) considera que os cinco primeiros modos de suspensão de juízo se referem ao sujeito enquanto os quatro seguintes ao objeto. O décimo, segundo ele, se refere aos dois, conforme demostrado no Quadro 1.

O processo de validação do design pode ser observado em cada modo de se evidenciar a incapacidade dos sentidos, enumerado por Enesidemo. Como projetista, para validar seu processo criativo, o designer precisa ser cético e considerar aspectos que influenciam nas diferentes percepções do mundo, como aqueles pontuados pela filosofia cética. Ao projetar produtos, processos ou serviços, o designer deve duvidar de sua percepção de mundo e considerar diferentes aspectos que determinam esta visão.

O Quadro 2 apresenta um exercício de apropriação dos modos que evidencia a incapacidade dos sentidos, enumerados por Enesidemo, por meio do design. Exemplos de projetos de produtos, processos ou serviços onde o designer se utiliza do ceticismo para empreender soluções pertinentes à diversidade de percepções da realidade.

Quadro 02- Exercício de apropriação dos modos do ceticismo 


\begin{tabular}{|c|c|c|}
\hline $\begin{array}{l}\text { DEFINIC̣ÃO } \\
\text { DO MODO }\end{array}$ & $\begin{array}{l}\text { CONTEXTO } \\
\text { DO DESIGN }\end{array}$ & EXEMPLO APLICADO \\
\hline $\begin{array}{l}\text { 1. A diversidade } \\
\text { dos animais: "A } \\
\text { conformação dos } \\
\text { órgãos sensoriais } \\
\text { apresenta uma grande } \\
\text { diversidade entre os } \\
\text { animais. A percepção } \\
\text { do mundo exterior } \\
\text { deve, portanto, variar } \\
\text { de uma espécie para } \\
\text { outra". (VERDAN, } \\
2008, \text { p. 40). }\end{array}$ & $\begin{array}{l}\text { Projetos de design } \\
\text { voltados a animais, } \\
\text { considerando sua } \\
\text { especificidade } \\
\text { de percepção. }\end{array}$ & $\begin{array}{l}\text { Apito ultrasônico para } \\
\text { adestramento de cães (só } \\
\text { eles conseguem ouvi-los). } \\
\text { Figura 01- Apito ultrasônico. }\end{array}$ \\
\hline $\begin{array}{l}\text { 2. A diversidade } \\
\text { dos homens: "Há, } \\
\text { entre os seres } \\
\text { humanos, diferenças } \\
\text { de constituição e } \\
\text { de temperamento } \\
\text { acarretando diferenças } \\
\text { de sensação e de } \\
\text { apreciação". (VERDAN, } \\
\text { 2008, p. 40). }\end{array}$ & $\begin{array}{l}\text { Projetos que } \\
\text { permitem a } \\
\text { interferência do } \\
\text { usuário em sua } \\
\text { composição, } \\
\text { considerando sua } \\
\text { necessidade de } \\
\text { expressão individual. }\end{array}$ & $\begin{array}{l}\text { Tênis com canetas especiais } \\
\text { para customização. } \\
\text { Figura 02- Customização } \\
\text { de produtos. }\end{array}$ \\
\hline $\begin{array}{l}\text { 3. A diversidade dos } \\
\text { sentidos: "Num mesmo } \\
\text { homem a apreciação } \\
\text { dada pelos diferentes } \\
\text { órgãos sensoriais está, } \\
\text { às vezes, sujeita a } \\
\text { variações". (VERDAN, } \\
2008, \text { p. 40). }\end{array}$ & $\begin{array}{lr}\text { O design } & \text { sensorial } \\
\text { considera } & \text { a } \\
\text { combinação } & \text { entre } \\
\text { sabores, } & \text { sons, } \\
\text { texturas e } & \text { imagens } \\
\text { coerentes } & \text { com uma } \\
\text { única mensagem. }\end{array}$ & $\begin{array}{l}\text { Design sensorial para a composição } \\
\text { da marca. } \\
\text { Figura }\end{array}$ \\
\hline
\end{tabular}

Fonte: Autoria própria (2013).

Burdek (1999) afirma que o processo de desenvolvimento de um objeto 
de design reflete as condições sob as quais surgiu: o contexto histórico, social e cultural, as limitações da técnica e da produção, os requisitos ergonômicos, ecológicos, os interesses econômicos, políticos e até as aspirações artísticas.

O exercício apresentado no Quadro 1 demonstra o esforço do design em atender a diferentes demandas considerando inúmeros aspectos que podem interferir na leitura do entorno. O ceticismo, neste caso, existe do designer em relação a sua própria percepção, ele duvida daquilo que observa para reconhecer a diversidade de observações.

Além da validação, o ceticismo também pode ser observado no conceito de melhoria contínua. Caffyn e Bessant (1996) descrevem o conceito de melhoria contínua como um processo, em toda a empresa, focado na inovação incremental e contínua. O pensamento cético contribui para a desconfiança em relação a melhoria de um processo e produto. A dúvida constante proposta pelo ceticismo pode ser tomada pelo design quanto a sua resolutividade: será que este produto, processo ou serviço pode responder melhor às demandas para as quais se propõe? Através desta pergunta incessante, é possível alterar produtos constantemente.

Conceitos de melhoria contínua e inovação são relacionados por Mesquita e Alliprandini (2003). A busca pelo novo, portanto, também se relaciona ao ceticismo, à medida que um projeto atual precisa ser constantemente validado.

\section{CONSIDERAC̣ÕES FINAIS}

A aplicação da filosofia no design permite uma reflexão que nos dispõe a analisar a prática do design quanto ao seu método e os resultados que apresenta. Embora não haja possibilidade de retomarmos o ceticismo, tal qual se propõe em sua total suspensão de juízo, na ciência moderna; sua atitude investigativa e dubitativa frente à razão humana alcançar realidades absolutas foi a base para filósofos como Emmanuel Kant (1724-1804) formularem "categorias" de pensamento corroborando a ciência em seu sentido moderno.

No contexto do design, a influência do caráter cético é entendida pela validação, conforme demostrado por exemplos práticos, onde se evidenciou o uso dos fundamentos lançados por Agripa e Enesidemo em seus tropos ou modos. Com esta compreensão, o ceticismo nos leva a transitar entre a certeza e incerteza do ato da projetação sem, no entanto, se recusar a buscar um modelo ideal, a verdade e assim a ataraxia. Esta última talvez seja oriunda da própria atitude dubitativa do cético e podemos dizer também do designer. Com esta 
reflexão podemos compreender o cerne de disciplinas e métodos de design, cita-se: a qualidade total, design thinking, testes e análises de uso no contexto, diagramas de causa e efeito, entre outros que dispõe da mesma atitude mental dubitativa cética. Dessa forma, podemos afirmar que o ceticismo dubitativo está intrínseco no método, da mesma forma no design onde,

\begin{abstract}
Todo passo metodológico deve (ou deveria em tese) ser desenvolvido com uma hipótese de trabalho, ensaiada e avaliada dentro do contexto em que ela se opera. A avaliação da eficácia de cada passo deveria realizar-se não somente comparando as ações desenvolvidas com as intencionadas, mas também os resultados perseguidos com os obtidos (MERINO; GONTIJO; MERINO, 2011, p. 71).
\end{abstract}

Estudos como este que propõem a prática da reflexão e da contextualização entre a filosofia e o design poderão servir como base em pesquisas relacionadas a métodos, práticas projetuais e melhoria contínua. Também relaciona-se a aplicação da reflexão no modo como pensamos e fazemos o design, constituindose numa expertise profissional do designer por seu olhar investigativo mediante os problemas e situações.

\title{
REFERÊNCIAS
}

ALMEIDA, Custódio. Hermenêutica e dialética: dos estudos platônicos ao encontro com Hegel. Porto Alegre: EDIPUCRS: 2002.

ARGAN, Giulio Carlo. A história na metodologia do projeto. Revista Caramelo, São Paulo, n. 6, p. 156-170, 1993.

CONVERSE ALL STAR. Hands On: Evelyn Negahamburguer. Disponível em: <http://www.Converseallstar.com.br/blog/tag/customizacao/> Acesso em: Jun. 2013

BURDEK, Bernhard. Diseño: história, teoría y práctica del diseño industrial. 2. ed. Barcelona: Editorial Gustavo Gili, 1999.

CAFFYN, S.; BESSANT, J. A capability-based model for continuous improvement. In: INTERNATIONAL CONFERENCE OF THE EUROMA, 3th., 1996. Proceedings... London, 1996.

CHOCOLADESIGN. Disponível em:<http://chocoladesign.com>. Acesso em: Jun. 2013 
DUTRA, Luiz Henrique de Araújo. Oposições filosóficas, a epistemologia e suas polêmicas. Florianópolis: Ed. UFSC, 2005.

FONTOURA, Antônio M. Algumas reflexões sobre o design, a arte, a ciência e o senso comum. Revista ABC Design, São Paulo, ago. 2009. Disponível em:<http://abcdesign.com.br/ por-assunto/teoria/algumasreflexoes-sobre-o-design-a-arte-a-ciencia-e-o-senso-comum/>. Acesso em: 21 mar. 2013.

GIL, Antonio Carlos. Como elaborar projetos de pesquisa. 4. ed. São Paulo: Atlas, 2008.

THE HISTORY of Toulouse Lautrec. Disponível em:<http://www.ehow. com/ about_5087028_history-toulouse-lautrec.html>. Acesso em: Jun. 2013.

INSTITUTE OF INFORMATION MANAGEMENT. What is Design Thinking?. Disponível em:<http://dthsg.com/what-is-design-thinking/>. Acesso em: Jun. 2013

LÖBACH, Bernard. Design industrial: bases para a configuração dos produtos industriais. Rio de Janeiro: Ed. Edgard Blucher, 2001.

LAKATOS, Eva Maria; MARCONI, Marina de Andrade. Metodologia científica. 2. ed. São Paulo: Atlas, 1995.

LANA, Sebastiana Luiza Bragança. A complexidade dos métodos em design. In: MORAES, Dijon; DIAS, REGINA Alvares; BOM CONSELHO, Rosemary (Org.). Cadernos de estudos avançados em design. Barbacena: EdUEMG, 2011. p. 53-65.

MERCADO LIVRE. Apito ultrasônico. Disponível em:<http://produto. mercadolivre.com.br/ MLB-465334509-apito-ultrasonico-adestramentode-ces-_JM>. Acesso em: Jun. 2013

MERINO, Giselle; GONTIJO, Leila Amaral; MERINO, Eugênio. O percurso do design: no ensino e na prática, na minha dissertação. In: MORAES, Dijon; DIAS, REGINA Alvares; BOM CONSELHO, Rosemary (Org.). Cadernos de estudos avançados em design: design e método. Barbacena: EdUEMG, 2011. p. 67-86. 
empresas da indústria de autopeças. Gestão e Produção, São Carlos, v. 10, n. 1, p. 17-33, 2003.

MUNARI, Bruno. Das coisas nascem coisas. São Paulo: Martins Fontes, 1998.

NET2 DESING. Portfolio: Quilmes. Disponível em:<http://http://www. n2dsite.com/>. Acesso em: Jun. 2013.

NORMAN, Donald. O design do dia a dia. Tradução de Ana Deiró. Rio de Janeiro: Rocco, 2006.

PALADINI, Edson Pacheco. Qualidade da qualidade: teoria e prática. 2 ed. São Paulo: Atlas, 2004.

PAPANEK, Victor. O que é design? Revista Arquitetura, Sao Leopoldo, ano 1, n. 5, 1995.

RUIC. Gabriela. Internet zomba da Apple e seu novo Mac Pro. Exame. com, 12 jun. 2013. Disponível em: <http://exame.abril.com.br/ tecnologia/noticias/internet-zomba-da-apple-e-seu-novo-mac-pro> Acesso em: Jun. 2013

SOUZA, Pedro Luiz Pereira. Notas para uma história do design. 2. ed. Rio de Janeiro: 2AB, 2008.

TEIXEIRA, Carlos. Prática reflexiva revisitada. In: MORAES, Dijon; DIAS, REGINA Alvares; BOM CONSELHO, Rosemary (Org.). Cadernos de estudos avançados em design. Barbacena: EdUEMG, 2011. p. 23-33.

VERDAN, André. O ceticismo filosófico. Florianópolis: Ed. Da UFSC, 1998.

ZANETTE, Edgard Vinícius Cacho. O ceticismo pirrônico e a classificação das filosofias possíveis. Theoria Revista Eletrônica de Filosofia, Pouso Alegre, n. 5, p. 142-150, 2010. Disponível em: <http://www.theoria.com. br/edicao0510/o_ceticismo_pirronico.pdf/>. Acesso em: 5 jun. 2013. 


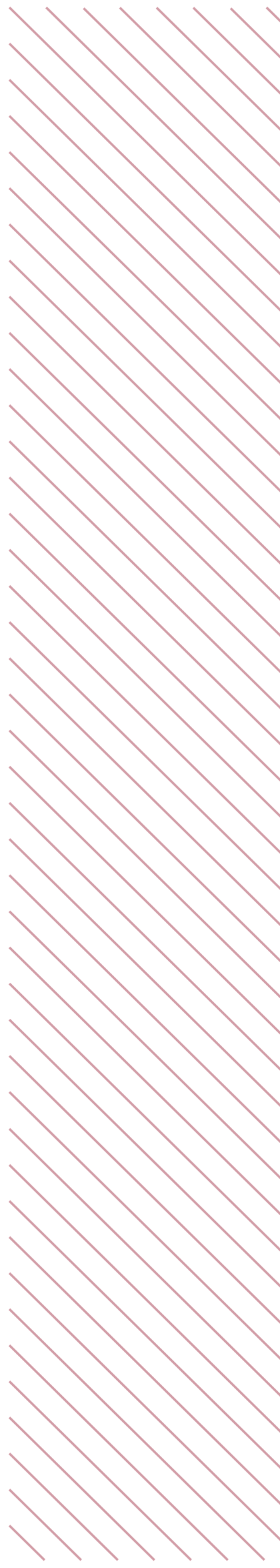

